University of Nebraska - Lincoln

DigitalCommons@University of Nebraska - Lincoln

Papers in Veterinary and Biomedical Science

Veterinary and Biomedical Sciences,

Department of

2009

\title{
Spontaneous Idiopathic Arteritis of the Testicular Artery in Raccoons (Procyon lotor)
}

\author{
A. N. Hamir \\ National Animal Disease Center, Agricultural Research Service, United States Department of Agriculture \\ M. V. Palmer \\ USDA National Animal Disease Center, Mitchell.Palmer@ars.usda.gov \\ H. Li \\ Washington State University \\ J. Stasko \\ National Animal Disease Center, Agricultural Research Service, United States Department of Agriculture \\ D. G. Rogers \\ University of Nebraska-Lincoln, drogers1@unl.edu
}

Follow this and additional works at: https://digitalcommons.unl.edu/vetscipapers

Part of the Biochemistry, Biophysics, and Structural Biology Commons, Cell and Developmental Biology Commons, Immunology and Infectious Disease Commons, Medical Sciences Commons, Veterinary Microbiology and Immunobiology Commons, and the Veterinary Pathology and Pathobiology Commons

Hamir, A. N.; Palmer, M. V.; Li, H.; Stasko, J.; and Rogers, D. G., "Spontaneous Idiopathic Arteritis of the Testicular Artery in Raccoons (Procyon lotor)" (2009). Papers in Veterinary and Biomedical Science. 143. https://digitalcommons.unl.edu/vetscipapers/143

This Article is brought to you for free and open access by the Veterinary and Biomedical Sciences, Department of at DigitalCommons@University of Nebraska - Lincoln. It has been accepted for inclusion in Papers in Veterinary and Biomedical Science by an authorized administrator of DigitalCommons@University of Nebraska - Lincoln. 


\title{
Spontaneous Idiopathic Arteritis of the Testicular Artery in Raccoons (Procyon lotor)
}

\author{
A. N. Hamir, M. Palmer, H. Li, J. Stasko, and D. G. Rogers \\ National Animal Disease Center, Agricultural Research Service, United States Department of \\ Agriculture, Ames, IA (ANH, ${ }^{1}$ MP, JS); Animal Disease Research Unit, USDA-Agricultural Research \\ Service, Washington State University, Pullman, WA (HL); and Department of Veterinary and \\ Biomedical Sciences, Veterinary Diagnostic Center, University of Nebraska, Lincoln, NE (DGR)
}

\begin{abstract}
The testes and the spermatic cord of raccoons (Procyon lotor, kits to adult breeders; $\mathrm{n}=$ 48) were examined. Segmental arteritis confined to the extratesticular portions of the testicular artery was present in raccoons of all ages. The arterial changes were seen in laboratory-confined experimental and control animals as well as in wild-caught raccoons. The lesions consisted of proliferative endarteritis with presence of inflammatory cells within the intima, media, and the adventitial regions of most affected vessels. Some aspects of the proliferative arterial lesions were reminiscent of systemic necrotizing vasculitis (polyarteritis nodosa), an immunologically mediated condition of animals and humans. Etiologic agents were not identified at the affected sites. Arteritis was not attributed to the administration of infectious agents because it was present in raccoons of all age and origin. To our knowledge multifocal arteritis confined to the testicular artery has not previously been documented in raccoons.
\end{abstract}

Key words: Arteritis; extratesticular artery; proliferative arteritis; raccoons (Procyon lotor).

Raccoons (Procyon lotor) are highly adaptable omnivores that are found throughout North America and in some areas of Europe and Asia where they were introduced in the 1960s. ${ }^{1}$ Raccoons are nocturnal and are found in urban and rural areas of the USA. They have been used as sentinels to monitor our immediate environment for pollutants ${ }^{2}$ and are being evaluated as models for the study of transmissible spongiform encephalopathies (TSEs; prion diseases) of animals., ${ }^{4,5}$

Arteritis or vasculitis, in general, is morphologically characterized by inflammatory cellular infiltrate in the walls of blood vessels and can be a component of many disorders in both humans and animals. Unlike in humans, immune-mediated causes of vasculitis in animals are not common ${ }^{3}$ and the etiology and pathogenesis of most vasculitides remains undetermined. ${ }^{8}$

This report documents microscopic findings of multifocal extratesticular arteritis in raccoons of different age groups that were used in transmission studies of TSEs (scrapie, transmissible mink encephalopathy, and chronic wasting disease) ${ }^{4,5}$ as well as in free-ranging raccoons.

\footnotetext{
${ }^{1}$ Present address: Department of Veterinary Medicine and Surgery, Unit 63, M. D. Anderson Cancer Center, Houston, TX.
}

\section{Materials and Methods}

Between 2000 and 2007, 48 male raccoons of different age groups (groups A to E; Table 1) were examined for the presence of extratesticular arteritis. The raccoons were either purchased from a commercial breeder in central Iowa or were live-trapped in the area surrounding the National Animal Disease Center (NADC), Ames, Iowa (Table 1). Raccoons from the breeder were used for experimental transmission studies (agents of TSEs) and included uninfected control animals. ${ }^{4,5}$ All experimental raccoons were housed with their respective groups in a biosafety level 2 containment facility at NADC. Raccoons were fed dry dog food (Premium formula, PMI Nutrition Inc., Brentwood, MO) twice a day, and clean water was available ad libitum.

The formalin-fixed raccoon testicles and spermatic cords (examined one testicle per animal), obtained at the time of castration, were bisected longitudinally and processed for routine histopathology. The tissues were embedded in paraffin wax, sectioned at $4 \mu \mathrm{m}$, and stained with HE. Selected sections were also stained with Gram, periodic acid-Schiff (PAS), and Gomoris methamine silver (GMS) stains and also were labeled by immunohistochemical (IHC) methods to detect presence of antigen for Chlamydia. For the latter, the primary polyclonal antiserum obtained from rabbits that had been hyperimmunized with ovine abortion strains B577 and OSP of Chlamydophila abortus was purified by column chromatography (CM Affi-Gel Blue, Bio-Rad Laboratories, Richmond, CA), and used as primary antibody at a 
Table 1. Age, source, and number of raccoons with histologic presence of arteritis in the extratesticular artery.*

\begin{tabular}{lcllrl}
\hline \hline Group & Age (months) & Source† & Experimental Inoculation & No. Examined & $\begin{array}{l}\text { No. with } \\
\text { Arteritis }\end{array}$ \\
\hline A & 2.5 & Breeder & No & 17 & $1(6 \%)$ \\
B & 5 & Breeder & Yes (Spiropl.) & 14 & $1(7 \%)$ \\
C & 7 & Breeder & Yes (Sc or CWD) & 5 & $5(100 \%)$ \\
D & $12-24$ & Free ranging & No & 6 & $1(17 \%)$ \\
E & $>84$ & Breeder & No & 6 & $1(17 \%) \ddagger$ \\
Total & & & & 48 & $9(18 \%)$ \\
\hline
\end{tabular}

* Spiropl. = inoculated intracerebrally with Spiroplasma murium. Sc = inoculated intracerebrally with sheep scrapie agent. $\mathrm{CWD}=$ inoculated intracerebrally with chronic wasting disease (CWD) agent.

$\dagger$ Both the breeder and free-ranging raccoons were obtained from central Iowa.

\$ Lesion in this raccoon appeared to have been partially resolved.

dilution of 1:750 in Tris buffer. Immunostaining of tissue sections was performed as previously described. ${ }^{7}$ Performance controls incorporated into each staining procedure included sections of ovine placenta with large numbers of C. abortus (positive tissue control) and the substitution of normal rabbit serum diluted 1:750 in Tris buffer for antiChlamydophila antibody (negative serum control). Selected paraffin-embedded tissue sections of two raccoons with arteritis were examined by nested polymerase chain reaction (PCR) using degenerate consensus primers targeting a region of herpesvirual DNA polymerase gene ${ }^{9}$ for any herpesvirus infection and by transmission electron microscopy (TEM). For the latter, the tissues were deparaffinized. They were placed in $2.5 \%$ glutaraldehyde in cacodylate buffer, and then in $1.0 \%$ osmium tetroxide in cacodylate buffer, and embedded in Epon. Thick sections $(1 \mu \mathrm{m})$ were stained with toluidine blue and selected areas were thin sectioned, stained with 5\% uranyl acetate in methanol and lead citrate, and examined with a transmission electron microscope.

\section{Results}

Testicles of 48 male raccoons of different ages were examined. Gross lesions were not detected. On microscopic examination, 9 raccoons $(18 \%)$ had extratesticular arteritis (Table 1; Figs. 1-5). Because both formalin-fixed testicles from each raccoon were not available for examination, it was not possible to indicate whether the arteritis was present bilaterally. Although the lesions were observed in all age groups, the prevalence appeared to be higher $(100 \%)$ in juveniles ( 7 months of age; group C; Table 1).

Morphologically, the arteritis was usually multifocal and segmental (Figs. 1-5), but occasionally it appeared to involve the intima circumferentially (Fig. 1). Lesions were observed in both the small and large vessels (Fig. 3). Very often a spectrum of mild to severe lesions, as well as active and chronic foci of inflammation, were seen in a single section (Figs. 2, 3). The inflammation appeared to origi- nate in the adventitia (Fig. 2) and extended into the arterial wall. Eventually, there was deposition of fibrous connective tissue in the subendothelial areas of the affected vessels (Figs. 1, 3). Although in many of the affected arteries there was narrowing of the lumina, none of the vessels appeared to be occluded (Figs. 1, 3, 5). The inflammatory cells were predominantly macrophages and lymphocytes with occasional plasma cells and rare eosinophils (Fig. 2). Pathogenic organisms were not detected in any of the examined sections.

Histochemical stains (Gram, PAS, GMS), IHC for Chlamydia, and PCR for herpesvirus were negative for microorganisms or their products. TEM examination of tissues confirmed the presence of arteritis and periarteritis, but did not reveal any pathogenic organisms.

\section{Discussion}

Raccoons are highly adaptable nocturnal mammals. Because they share our immediate environment, they are considered good monitors of zoonotic diseases and environmental contamination due to pollutants. ${ }^{2}$ Therefore, documentation of unusual conditions in raccoons is desirable.

Inflammation of blood vessels (vasculitis) can be caused by various agents including viruses, bacteria, fungi, and parasites. ${ }^{3,10}$ In the present investigation, there was no evidence of the infectious agents commonly associated with vasculitides in animals. Most vasculitides are thought to have an immune-mediated basis., ${ }^{3,10}$ Therefore, it may suggest that immune-mediated mechanisms may have contributed in the formation of these lesions. However, in the present study the distribution of only the extratesticular portion of the artery may make it possible that the vasculitides of the spermatic cord in raccoons may have been induced by trauma, either self-inflicted or otherwise. 

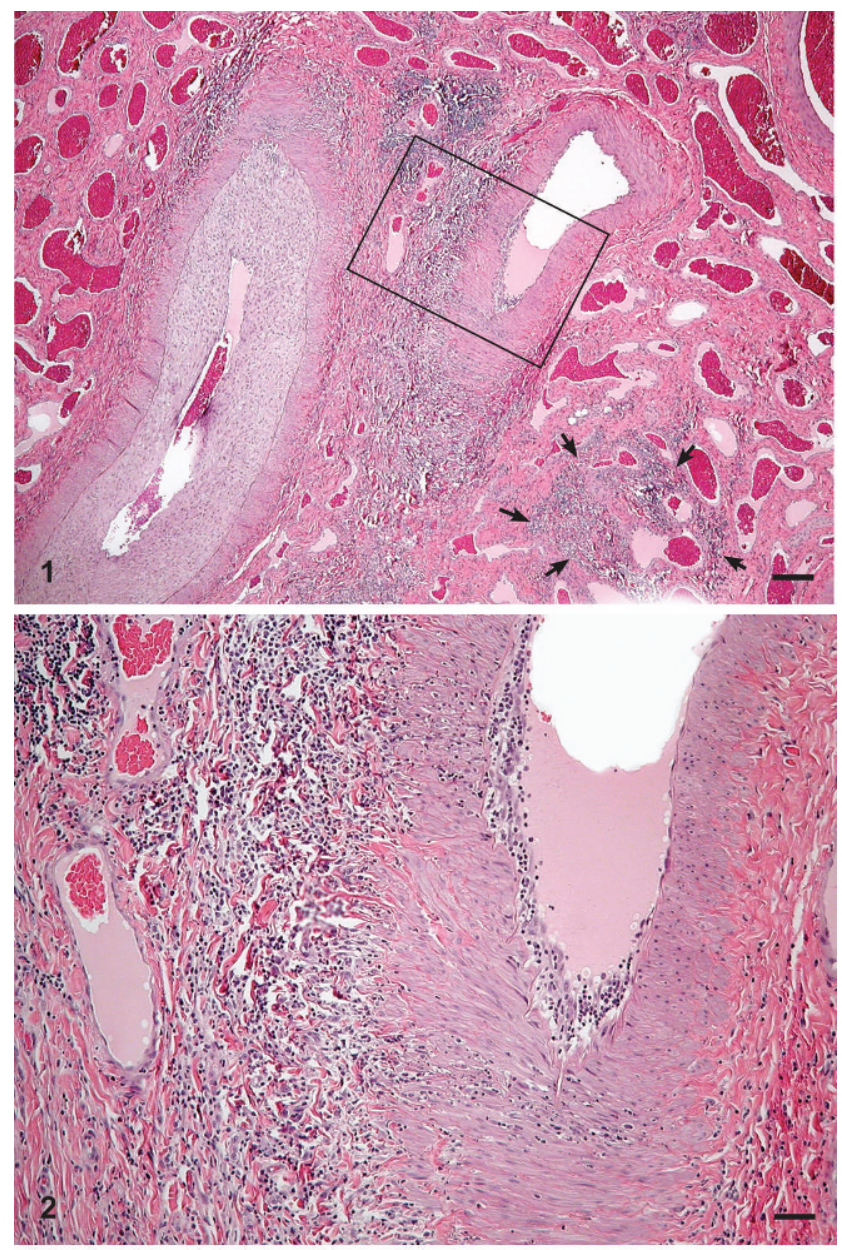

Fig. 1. Extratesticular artery; raccoon No. 02-147. Two thick-walled and a few thin-walled (arrows) blood vessels show extensive multifocal perivascular inflammatory cellular infiltration. One of the larger arteries has extensive circumferential proliferation of endothelium. HE. Bar $=120 \mu \mathrm{m}$.

Fig. 2. Extratesticular artery; raccoon No. 02-147. Higher magnification of the rectangular area marked in Fig. 1. In the perivascular tissue there is extensive infiltration of inflammatory cells which extend into the wall and the endothelial areas. HE. Bar $=50 \mu \mathrm{m}$.

In the present study, although $18 \%$ of raccoons were found to have arteritis of the extratesticular artery, the prevalence was rather variable in different groups. However, as only one testicle per raccoon was collected at castration, it is likely that the actual incidence of this condition may have been higher if both testicles from each raccoon were examined. Raccoons inoculated with the agents of TSEs (group C) had 100\% involvement with arteritis (Table 1). Although experimental transmission of TSEs (transmissible mink encephalopathy and sheep scrapie) have been documented in raccoons, ${ }^{4,5}$ none of the reports have documented presence of arteritis in any organs of these
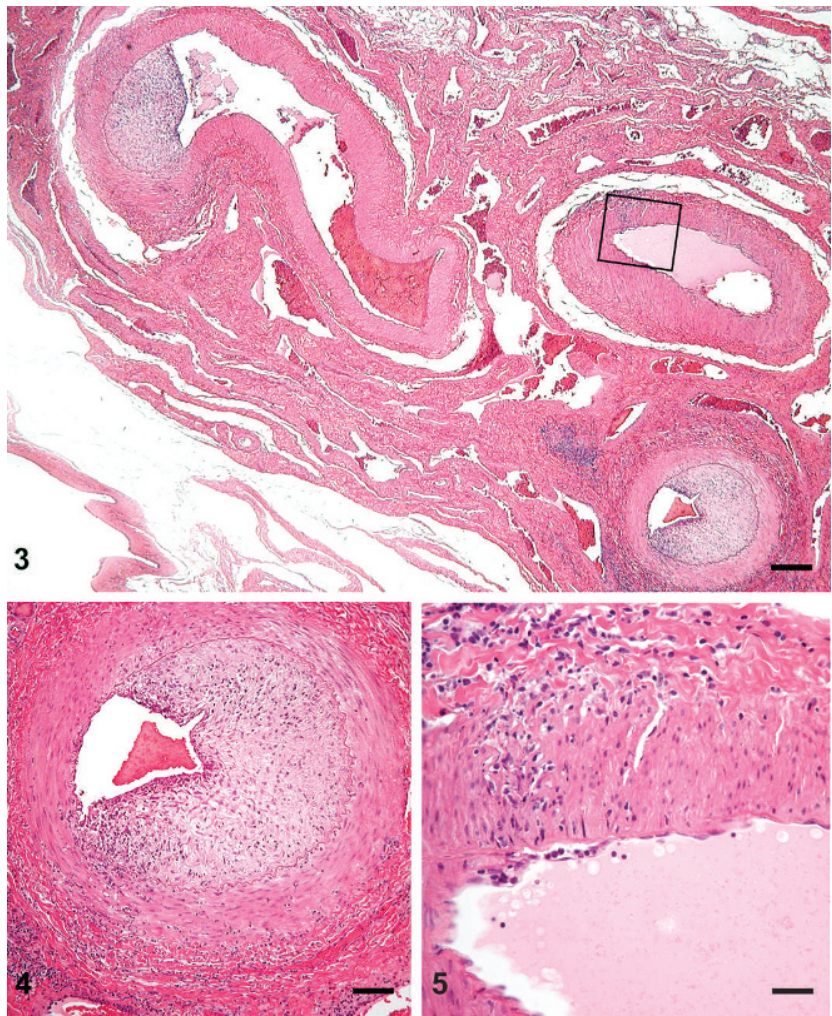

Fig. 3. Extratesticular artery; raccoon No. 02-146. Cross-sections of three medium-sized arteries show moderate perivascular inflammatory infiltrate and extensive segmental proliferation of endothelium. HE. Bar $=120 \mu \mathrm{m}$.

Fig. 4. Extratesticular artery; raccoon No. 02-146. Higher magnification of one of the arteries shown in Fig. 3. There is moderate inflammatory cellular infiltrate in the perivascular tissue extending into the wall of the vessel. Note the marked narrowing of the lumen of the artery by fibrous connective tissue. HE. Bar $=70 \mu \mathrm{m}$.

Fig. 5. Extratesticular artery; raccoon No. 02-146. Higher magnification of rectangular area marked in Fig. 3 . There is a focal area in the wall of the artery with inflammatory infiltrate. HE. Bar $=25 \mu \mathrm{m}$.

experimental animals when euthanatized at the end of the studies. ${ }^{4,5}$

Inflammation of extratesticular artery in raccoons has not previously been reported. The observation of such a condition in various age groups of raccoons indicates that the agents or conditions responsible for inciting this lesion would appear to be fairly widespread in central Iowa. In some of the examined raccoons, the affected areas of the arteries revealed extensive proliferation of intima together with the cellular inflammatory component that resembled the morphologic lesion of systemic necrotizing vasculitis (polyarteritis nodosa, periarteritis, panarteritis, idiopathic febrile necrotizing arteritis). ${ }^{3}$ This condition has been sporadically documented in all species of domestic 
and laboratory animals., Although the cause of this condition has not been established, an immunologic basis is suspected as an instigating factor. However, in the examined raccoons the arteritis differed from that seen with polyarteritis in other animals. For example, none of the affected blood vessels revealed lesions that completely occluded the lumina of vessels or showed obvious lesions of fibrinoid necrosis in the media of the affected vessels. These differences may indicate differences in the etiopathogeny of the lesions, or in the stage of the lesions. Finally, because most of the raccoons in this investigation were laboratory-confined and were in gang cages, this may suggest stress as a possible factor in inducing the vascular pathology, which has been previously suggested as a possible cause of vasculitis in laboratory-confined dogs. ${ }^{3}$

\section{Acknowledgements}

We thank the late Dr. L. Nusz and Dr. J. Laufer for clinical assistance; Dr. Marcus Kehrli Jr. for constructive comments and for his enthusiastic support and James Fosse for the photomicrographs. Expert technical assistance was provided by Martha Church, Ginny Montgomery and the TSE animal caretakers. This study was carried out under the guidelines of the institutional Animal Care and Use Committee at National Animal Disease Center. Mention of trade names or commercial products in this article is solely for the purpose of providing specific information and does not imply recommendation or endorsement by the US Department of Agriculture.

\section{References}

1 Aliev FF, Sanderson GC: Distribution and status of the raccoon in Soviet Union. J Wildl Manag 30:497-502. 1966
2 Bigler WM, Jenkins JH, Cumbie PM, Hoff GL, Prather EC: Wildlife and environmental health: raccoons as indicators of zoonoses and pollutants in the southeastern United States. J Am Vet Med Assoc 167:592-597. 1975

3 Clemo FAS, Evering WE, Snyder PW, Albassam MA: Differentiating spontaneous from drug-induced vascular injury in the dog. Toxicol Pathol 31:25-31. 2003

4 Hamir AN, Miller JM, Cutlip RC, Stack MJ, Chaplin MJ, Jenny AL, Williams ES: Experimental inoculation of scrapie and chronic wasting disease agents to raccoons (Procyon lotor). Vet Rec 153:121-123. 2003

5 Hamir AN, Miller JM, O'Rourke KI, Bartz JC, Stack MJ, Chaplin MJ: Transmission of transmissible mink encephalopathy (TME) to raccoons (Procyon lotor) by intracerebral inoculation. J Vet Diagn Invest 16:57-63. 2004

6 Maxie MG, Robinson WF: Cardiovascular system. In: Pathology of Domestic Animals, ed. Maxie MG, 5th ed., vol. 3, pp. 1-105. Elsevier Saunders, Philadelphia, PA, 2007

7 Rogers DG, Andersen AA, Hunsaker BD: Lung and nasal lesions caused by a swine chlamydial isolate in gnotobiotic pigs. J Vet Diagn Invest 8:45-55. 1996

8 Snyder PW, Kazacos EA, Scott-Moncrieff JC, HogenEsch H, Carlton WW, Glickman LT, Lelsburg PJ: Pathologic features of naturally occurring juvenile polyarteritis in beagle dogs. Vet Pathol 32:337-345. 1995

9 VanDevanter DR, Warrener P, Bennett L, Schultz ER, Coulter S, Garber RL, Rose TM: Detection and analysis of diverse herpesviral species by consensus primer PCR. J Clin Microbiol 34:1666-1671. 1996

10 Van Vleet JF, Ferrans VJ: Circulatory system. In: Pathologic Basis of Veterinary Disease, ed. McGavin MD and Zachary JF, 4th ed., pp. 556-611. Mosby Elsevier, St. Louis, MO, 2007

Request reprints from Dr. A. N. Hamir, Department of Veterinary Medicine and Surgery-Unit 63, M. D. Anderson Cancer Center, 1515 Holcombe Boulevard, Room 4055C, Houston, TX 77030 (USA). E-mail: ahamir@mdanderson. org. 